\title{
Exploring Variation of Maintenance Action and Its Impacts on Emission and Cost in Jakarta City
}

\author{
Sudarmanto Budi Nugroho (Corresponding author) \\ Graduate School for International Development and Cooperation, Hiroshima University \\ 1-5-1 Kagamiyama, Higashi Hiroshima, 739-8529, Japan \\ Tel: 81-82-424-4342 E-mail: sbntotok@hiroshima-u.ac.jp
}

Akimasa Fujiwara

Graduate School for International Development and Cooperation, Hiroshima University

1-5-1 Kagamiyama, Higashi Hiroshima, 739-8529, Japan

Tel: 81-82-424-6921 E-mail: afujiw@hiroshima-u.ac.jp

Junyi Zhang

Graduate School for International Development and Cooperation, Hiroshima University

1-5-1 Kagamiyama, Higashi Hiroshima, 739-8529, Japan

Tel: 81-82-424-6919Ｅ-mail: zjy@hiroshima-u.ac.jp

\begin{abstract}
Received: December 6, $2011 \quad$ Accepted: December 19, $2011 \quad$ Published: December 31, 2011
doi:10.5539/eer.v1n1p163 URL: http://dx.doi.org/10.5539/eer.v1n1p163
\end{abstract}

This research is partially supported by Global Environmental Leader Program, Hiroshima University.

\begin{abstract}
Local government of Jakarta issued a bylaw on air pollution controls for mobile sources, stipulates that all private car owners must get their vehicles' emission tested biennially. In consequence of non-compliance vehicle in emissions test, vehicle maintenance is essential. Vehicle owner should take an appropriate action in order to reduce pollutant level lower than standard. This study attempts to analyze economic aspect and emission level considerations come into making optimal choice of vehicle owner. First, we examine the influential factors of action taken in maintenance process of non-compliance vehicle on probability of vehicle to pass the second stage emissions test. Second, due to variation of actions taken in the maintenance process, we analyze impact on cost and explore components affects on variation of maintenance cost. Empirical analysis was done by using Inspection and Maintenance data in year 2000 which collected at several auto-mechanic shops in Jakarta city. The bivariate probit model was applied to examine impact of chosen alternatives on the probability to pass Hydrocarbon and Carbon Monoxide in second emission test. To examine variation of maintenance cost and explore components affects on cost, multilevel approach was applied. It is confirm that several actions may increase probability to pass emission test but on the same time reduce average cost. Other actions may simultaneously increase probability to pass emission test and also increase cost. It was also found some actions didn't have impact on emission test but on the other hand rise maintenance cost. Furthermore, some actions reduce probability to pass emission test but increase maintenance cost. Vehicle owner need to properly select actions in order to maximize benefit and minimize cost.
\end{abstract}

Keywords: Inspection and maintenance, Bivariate probit, Multilevel analysis, Jakarta city

\section{Introduction}

Externalities from transport sectors are widely recognized as a major problem in emerging Asian Megacities. There is growing concern about traffic congestion, noise and air pollution. The main approach to dealing with these externalities so far in Indonesia has been regulatory. The local government of Jakarta issued a bylaw on air 
pollution controls from mobile sources, stipulates that all private car owners must get their vehicles' emission tested biennially (Shimamora, 2006). This policy took effect since February 2006. It is main part of popularly known as the inspection and maintenance (I/M) program. Vehicle registered in Jakarta city must be subjected to Inspection/Maintenance test at mechanic garage twice a year. As incentive, an emissions certificate is required for extending vehicle's registration (BPLHD, 2005). The test consists of tailpipe emission test called idle emission test, an examination of certain components of evaporative emission system and a check to ensure that vehicle has not been tampered with. Any motor vehicle with emission rates of Hydrocarbon (HC) and Carbon Monoxide (CO) that exceed a set of Jakarta 's emission standards must be repaired to meet those standard in order to extend vehicle registration (Figure 1).

Implementation of inspection and emission program for in-use vehicle does not usually result in additional direct costs for governments. Usually, implementation costs transferred to passenger car owners. It requires policy makers to have a good idea of extra costs cause by Inspection and Maintenance program. Economists use term "marginal social cost" caused by transport activities (Harrington, 1996). The economic aspect and emission level considerations come into making the optimal choice. First, vehicle owner should approve offering actions to improve emission level suggested by mechanic workshop. Then, variation of action may affect on variation of maintenance cost. The number of repair parts, replace parts, other action taken in maintenance and vehicle conditions also affects significantly on actual cost. The only cost that can be estimated by actual expenditure data are cost of test and cost of repair. The other I/M cost components-time for travel, waiting time and repair timeare not observed in market activity. Of course such repair cost doesn't deal at all related cost of Inspection and Maintenance program, but at least or partially we could provide basic information to minimize cost and maximize emissions reduction.

It is critical to understand variation of maintenance actions and simultaneous effect on emission level and maintenance cost. First, this paper examine influential factors of maintenance actions to improve their emission level at a desire level refers to standards. Emission reduction depends on the proper action taken in maintenance process, vehicle characteristics, emissions load of Hydrocarbon (HC) and Carbon Monoxide (CO) need to be reduced at a certain level. We already performed studies based on individual action and its impact on emission test (Nugroho, 2010a) and comparison between repair and replacement of maintenance action combination on emission test results (Nugroho, 2010b). We also apply simple regression analysis of maintenance cost in those two papers (Nugroho, 2010a \&2010b). However, this paper apply simultaneous analysis of effect of maintenance action on emission and cost variations which never been examined in developing countries. Through this analysis, it is expected to provide recommendation of priority action to maximize improvement of vehicle emission by passing second emission test and try to minimize maintenance cost of vehicle owner. In the context developing cities, this study is useful to evaluate Inspection and Maintenance program in the early stage of implementation in Jakarta city

\section{Methodology}

\subsection{Inspection and maintenance of in-use vehicles}

Emission testing in Jakarta city was mainly base on the use of idle emission test. To perform idle-emissions tests, we refer to Indonesian Standard SNI 09-3678-1995 which was already revised to be SNI 19-7118.3.2005. These Indonesian standards developed based on International Organization for Standardization (ISO) 3930/OIML R99-instrument for measuring vehicle exhaust emission 2000- and United Nation for Economic Commission for Europe (UN-ECE). To prepare idle-emission test, passenger car exhaust pipe shouldn't have any leakage, under normal temperature of engine and ambient temperature in between $20^{\circ} \mathrm{C}-35^{\circ} \mathrm{C}$. Idle conditions means passenger car engine working without any acceleration of fuel system, neutral transmission position for manual type of passenger car, neutral transmission or parking position for automatic passenger car. At the same time, other passenger car accessories which influence to engine rotation were shut down. Vehicles exhaust gas measured by a gas analyzer to obtain the concentration or emissions levels of $\mathrm{CO}(\%)$ and $\mathrm{HC}(\mathrm{ppm})$. Road traffic in big cities in Indonesia is characterized with high congestion levels during day times. Thus, there is great number of vehicles operating at idle or stop-and-go driving conditions. We can assume that emission test results can be used to represent real world conditions at sites over-congested traffic that result in long idling times. It is suitable to represent current traffic situation in Jakarta city.

In typical I/M program, owner are required periodically to take vehicles subject to regulation at an inspection and maintenance station. Based on result of emission test, vehicles which fail to pass emissions test under inspection program are suggested to perform a maintenance process and then re-test their emissions. In Jakarta, one test always performed is a test of tailpipe emissions which directly examine emissions of vehicle. Two main 
pollutants which are subject to exhaust emission legislation are carbon monoxide (CO) and hydrocarbon (HC) (Table1). These emissions are worse from the spark-ignition engine than from compression ignition engine. This study only analyze the I/M program for spark-ignition engine (gasoline vehicle). Carbon monoxide and hydrocarbon represent around $1 \%$ of mean exhaust composition without catalytic converter in ECE-test (medium-size vehicle) (Abdel-Rahman, 1998). Emissions of CO are influenced primarily by air to fuel ratio. Emissions of $\mathrm{HC}$ are primarily due to incomplete combustion of hydrocarbon fuel. $\mathrm{HC}$ emissions are also formed due to quench effect, misfire as well as due to the detachment of lubricating film. One key parameter very effective in the formation of $\mathrm{CO}$ and $\mathrm{HC}$ is air-to-fuel ratio when fuel is burned (Rubin, 2001). In this study, air-to-fuel ratio (lambda) is taken as the stoichiometric amount. When air-to-fuel ratio is less than 1, it is impossible to burn all fuel as there is insufficient air. In this case, $\mathrm{CO}$ and $\mathrm{HC}$ should be emitted as products of incomplete combustion. Generally, air-to-fuel ratio is subject to passenger car maintenance conditions. Routine maintenance keeps air-to-fuel ratio near the stoichiometric amount, which automatically sustains passenger car' emissions at a desired levels. Air to fuel ratio always play a significant role in determining $\mathrm{CO}$ emission in our previous studies (Nugroho, 2010a).

\subsection{Bivariate probit model of impact of maintenance actions on the $2^{\text {nd }}$ emission test}

The bivariate probit regression analysis used to examine likelihood of $\mathrm{CO}$ and $\mathrm{HC}$ emission test results after performing maintenance actions. In our model, vehicles which successfully pass emission test after taking maintenance is defined as the effect of actions taking during process of vehicle repair, reduction of $\mathrm{CO}$ and $\mathrm{HC}$ refer to standards and its characteristics such as engine size, running kilometer per year, prior maintenance level. Using all independent variables, we propose a Bivariate binary Probit regression model of vehicle pass in the second emission test. Bivariate binary Probit regression model depends on simultaneous observation of two discrete binary observed-dependent variables, i.e., $y_{i l}$ and $y_{i 2}$, that indicates pass of emissions test of $\mathrm{CO}$ and $\mathrm{HC}$. Based on the observed dependent variables which take binary discrete values, underlying continuous dependent variables, $z_{i l}$ and $z_{i 2}$, can be expressed as:

$$
\begin{aligned}
& z_{i 1}=\boldsymbol{\beta}_{\mathbf{1}}^{\prime} \mathbf{x}_{\mathbf{i} 1}+\varepsilon_{i 1} \\
& z_{i 2}=\boldsymbol{\beta}_{\mathbf{2}}^{\prime} \mathbf{x}_{\mathbf{i} 2}+\varepsilon_{i 2}
\end{aligned}, y_{i j}=1 \text { if } z_{i j}>0, y_{i j}=0 \text { otherwise, } j=\{1,2\}
$$

Where $i$ denotes an observation; $\boldsymbol{\beta}$ and $\mathbf{x}$ stand for the vectors of parameters and independent variables respectively; $\varepsilon_{i 1}$ and $\varepsilon_{i 2}$ are random variates distributed jointly as standard. Bivariate Normal and a free correlation parameter, $\rho$, i.e., BNV $[0,0,1,1, \rho]$. Based on the equation given above, log- likelihood function of sample can be given as:

$$
\log L=\sum_{i} \log \Phi_{2}\left[q_{i 1} \boldsymbol{\beta}_{1}^{\prime} \mathbf{x}_{\mathbf{i} 1}, q_{i 2} \boldsymbol{\beta}_{2}^{\prime} \mathbf{x}_{\mathbf{i} 2}, q_{i 1} q_{i 2} \rho\right]
$$

Where $\Phi_{2}$ stands for the standard Bivariate Normal distribution; $q$ is an indicator variable such that $q_{i m}=2 y_{i m}-1$, $m=\{1,2\}$. The model was estimated by using LIMDEP Version 8.0 econometric software (Greene, 2002).

\subsection{Multilevel analysis of maintenance cost variations}

Maintenance cost refers to additional (non-regular) maintenance action in order to pass the emission test. This study attempts to analyze variation of maintenance cost spent by vehicle owner due to variation action taken during maintenance process and its impact on emission test results. This paper examines variation of maintenance cost among group as refer to Jakarta's standard and also among vehicles under similar category (Table 1). Furthermore, this article also explores factor affects on maintenance cost. To quantitatively assess properties of unobserved heterogeneity at various costs, this study focus on various components, which correspond to the degree of variation caused by unobserved heterogeneity at a level of vehicle by using actual cost reported by vehicle owner. To examine the components affects on maintenance cost variability, we use regression-based method a multilevel approach. The total variations of costs decomposed into three components: vehicle characteristics, variation of action taken in maintenance process, and variation of pollution reduction to achieve Jakarta's standard. Then, effects of each type of variation on maintenance cost are examined. Furthermore, how much of each variation can be explained by observed variables is also evaluated. The explanatory variables include action taken in maintenance process, vehicle emission load of both $\mathrm{CO}$ and $\mathrm{HC}$ and vehicle characteristic. To describe maintenance cost variations of vehicle group $i$, in multilevel analysis, model buildings strategies can be either top-down and bottom-up (Hox, 2010). In this study, we select bottom-up approach starts with a simplest model and proceed by adding parameters, which are tested for significance after 
they have been added. The advantage of bottom-up procedure is that it tends to keep the model simple. This situation may give easily interpreted estimation results. First, it starts with model without explanatory variables (called Null model). This model, the intercept-only model, is given by equation 3 :

$$
\mathrm{Y}_{\mathrm{ij}}=\gamma_{00}+\mu_{\mathrm{oj}}+\varepsilon_{\mathrm{ij}}
$$

Where $\gamma_{00}$ is regression intercept and $\mu_{\mathrm{oj}}$ and $\varepsilon_{\mathrm{ij}}$ are residuals at group and individual level. Altogether there are three effects to estimate: intercept, between-group variation in intercept $\left(\mu_{\mathrm{oj}}\right)$, and variation in individual-level $\left(\varepsilon_{i \mathrm{ij}}\right)$. In this study, 'group' means group of vehicle based on its own characteristic refers to Jakarta 's standard (Table 1) and 'individual' means vehicle under the similar group. Using the Null model, it possible to clarify the reason of "why maintenance cost are fluctuates?" based on component of variance. It is also gives estimate of interclass correlation $(\rho)$ among individual-level in group. The interclass correlation (ICC, $\rho$ ) is estimated by equation 4 :

$$
\sigma_{\mu 0}^{2} /\left(\sigma_{\mu 0}^{2}+\sigma_{\mathrm{e}}^{2}\right)
$$

Where $\sigma_{\mu 0}{ }^{2}$ is variance of group-level residuals $\sigma_{\mu 0}$ and $\sigma_{\mathrm{e}}{ }^{2}$ is variance of individual-level residual $\varepsilon_{\mathrm{ij}}$. Second step, analysis the model with all lower-level explanatory variables fixed (called as Full model) which means corresponding variance component of slopes are fixed at zero. This model is expressed by equation 5:

$$
\mathrm{Y}_{\mathrm{ij}}=\gamma_{00}+\gamma_{10} X_{\mathrm{jk}}+\mu_{\mathrm{oj}}+\varepsilon_{\mathrm{ij}}
$$

Where $\mathrm{Y}_{\mathrm{ij}}$ is dependent variable (maintenance cost) of every vehicle group $i$ paid by vehicle owner $j . \gamma_{00}$ and $\gamma_{10}$ are unknown parameters, $\mathrm{X}_{\mathrm{jk}}$ indicates explanatory variables including vehicle $j$ characteristics (e.g., vehicle age, engine size, running kilometer per year), pollutants $k(\mathrm{HC}$ and $\mathrm{CO}$ ) level need to be reduce to achieve allowable standard (as shown in equation 6), actions taken during maintenance process (e.g., repair or replace some engine parts, tune-up some engine parts, change engine oil and other action). The reduction of emission load (PNR) could be calculated by using equation 6 :

$$
\mathrm{PNR}_{\mathrm{k}}=\left\{\left(\mathrm{PLB}_{\mathrm{m}}-\mathrm{PS}_{\mathrm{ki}}\right) / \mathrm{PLB}_{\mathrm{m}}\right\} \times 100 \%
$$

Where $\mathrm{PNR}_{\mathrm{i}}$ stand for reduction of pollutant $i(\%) ; \mathrm{PLB}_{\mathrm{m}}$ is level of concentration of pollutant $k$ before taking maintenance; $\mathrm{PS}_{\mathrm{ki}}$ is emission standard of pollutant $k$ of vehicle under group $i$. $\varepsilon_{\mathrm{ij}}$ and $\gamma^{j}$ represent random components which indicate intra-group variation (error term), inter-vehicle variation, pollutants level variation and variation of actions, respectively. In this step, we assess contribution of each vehicle-level explanatory variable. The significance of each predictor can be tested and also possible to assess what changes occur in the first-level and second-level variance term. The model in second step is often denoted as variance component model, because it decomposes intercept variance into different components for each hierarchical level. In variance component model, regression intercept is assumed to vary across group, but regression slopes are assumed fixed. The chi-square test based on deviances of Null and Full models were used to test assumption whether variation across group is significant. At each step, it was decided which regression coefficients or (co)variances to keep on basis of significance test and change in the deviance. Whenever introduce explanatory variables in step 2, it is expected vehicle-level variance $\sigma_{\mathrm{e}}^{2}$ goes down. If the composition of groups with respect to explanatory variables is not exactly identical for all groups, we expect the group-level variance $\sigma_{\mu 0}{ }^{2}$ also to go down. Then, vehicle-level explanatory variables explain part of vehicle and part of group variance.

\section{Empirical Data}

This paper examines the influence of several actions taken in maintenance process in order to reduce $\mathrm{CO}$ and $\mathrm{HC}$ emissions. Data was collected from voluntary maintenance activities by vehicle owner at several auto mechanic shops in Jakarta city in year 2000. If a vehicle fails in the emission test, it should be repaired or perform an appropriate maintenance to achieve allowable emission standard. By using emission measurement data 'before and after' maintenance process, this paper examine influence of several actions recommended by technicians and approved by the owners to reduce $\mathrm{CO}$ and $\mathrm{HC}$ emissions. Total sample were 1504 vehicles, but only 1358 samples used in analysis due to data cleaning processes. Six hundred and seventy five vehicles fail in the first test and need a repair in order to improve their emission. We found 548 vehicles $(81.3 \%)$ among them which failed in the first emission test were successfully pass second emission test. In this study, only 675 data/samples of vehicles which fail in the $1^{\text {st }}$ emission test used to evaluate effectiveness of maintenance actions and its cost. It also found improvement of dummy variable of maintenance quality after maintenance process (Table 2). After repair, air-to-fuel ratio of vehicle nearly closed to ideal condition of engine. The carburetor vehicles is around $73.9 \%$ of total sample and middle size class of vehicle (1500-2000) cc is most popular group of vehicle owned in Jakarta city. Most of the vehicle owner uses their vehicles less than 20,000 kilometers per year. 
The maintenance action could be classified into three main categories which are repair, replacement and other. Repairing engine includes action taken to repair air filter, fuel's filter, spark-plug and 'platina'. Besides repairs, technician also recommends to replace some engine parts such as air filter, fuel filter, spark-ignition and also platina if it is necessary or they think that repairs were impossible or not improve condition. The other actions taken in maintenance process were follow-up action after repair or replacement engine parts such as tune-up carburetor of injection system, tune-up engine burning system, change engine oil. Vehicle owner should pay at least Rp 8, 000, - and maximum Rp 737, 000, - (1 USD=9,000 Rupiah) to test emissions and repair their vehicles. Instead of economic aspect, vehicle owner also need to consider achievement level since measurement of this achievement will determine the $2^{\text {nd }}$ emission test result. The action taken in maintenance process directly affects on cost, and optimum solution necessary for vehicle owner. It is also found the effectiveness of maintenance actions on improvement/reduce of emission level to a certain level which allowed by Jakarta's standard (Table 1 ) or in other word increasing probability to pass $2^{\text {nd }}$ emission test.

\section{Estimation Results and Discussion}

This study begins by evaluating efficiency of efforts taken during maintenance process on emission test. The Bivariate Probit regression analysis was conducted using explanatory variables of vehicle characteristics, reduction of pollutants to a desire level lower than emission standard and various actions as maintenance efforts on probability to pass $\mathrm{CO}$ and $\mathrm{HC}$ in the second stage of emission test. The explanatory variables of vehicle characteristics include variables of engine size class, running kilometer per year of passenger car, and dummy variable of current level of maintenance quality, and pollutant reduction of $\mathrm{HC}$ and $\mathrm{CO}$. In the second step, analysis of cost variation due to heterogeneity of action taken during maintenance process evaluated based on simultaneous effect of maintenance action on emission and cost.

\subsection{Bivariate probit model}

To examine effectiveness of maintenance action, bivariate probit regression analysis was conducted using independent variables of engine size class, running kilometer per year of passenger car, dummy variable maintenance quality and maintenance actions such as cleaning, replacement, engine tune-up, engine-oil change, reduction of pollutants (CO and $\mathrm{HC})$ and other actions taken at auto-mechanics shops. The information about process from fail to pass emission test $(\mathrm{CO}$ and $\mathrm{HC})$ were selected as dependent variables. The model was estimated to test for significance of inclusion of factors as maintenance-model for all non-compliance vehicles (675 samples). The disturbance correlation show negative value means some action may improve CO emission but on the same time reduce probability to pass $\mathrm{HC}$ emissions. It was found an inverse direction of constant term, repairing 'platina', and replacing 'platina' on the efforts to pass $\mathrm{HC}$ and $\mathrm{CO}$ emission test. However, in general, maintenance action increases almost $17 \%$ probability to pass both $\mathrm{CO}$ and $\mathrm{HC}$ simultaneously. Looking at Table 3 , three actions affect significantly on probability to pass both $\mathrm{CO}$ and $\mathrm{HC}$ simultaneously. Two action increase the probability which are 'repair platina' and 'replace platina'. In contrast, perform 'other' action may reduce probability to pass both $\mathrm{CO}$ and $\mathrm{HC}$. All variables of vehicle characteristics and also reduction of pollutant level are insignificant. In case of parameter $\mathrm{CO}$, efforts on maintenance process increase almost $90 \%$ probability to pass second emission test results. The dummy variable of maintenance quality before maintenance process is one of significant factor affect on probability to pass $\mathrm{CO}$ emission test. The reduction of pollutants ( $\mathrm{CO}$ and $\mathrm{HC})$ also influence probability to pass emission test of $\mathrm{CO}$. Increasing vehicle engine category reduce probability to pass $\mathrm{CO}$ in the second round test. Regarding on maintenance actions, 'repairing air filter' and 'tune-up engine's fire system ' increase probability and statistically significant to pass $\mathrm{CO}$ emission. In contrast, repairing and replacing 'platina' significantly reduce probability to pass $\mathrm{CO}$ emission test. On the other hand, repairing and replacing 'platina' and replacing air filter play a significant role on the effort to pass $\mathrm{HC}$ emission test. The replacement of 'spark' and 'other' maintenance gives negative influences on probability to pass $\mathrm{HC}$ emission test. Moreover, performs maintenance action may reduce probability to pass $\mathrm{HC}$ emission test results.

\subsection{Multilevel analysis of maintenance cost}

In this study, empirical analysis of variation properties of maintenance cost variation was done using revealed preference data from vehicle owner. In developing countries such as Indonesia where labor cost is cheap but price of engine parts is expensive, the owners usually ask auto-mechanic staff to try their best to maximize repairmen process rather than replacement with new parts to reduce maintenance cost. First, employ NULL Model, an intercept only and use R-package software to estimation the results (Table 4). The dependent variables maintenance cost, is expressed in thousand rupiah (1 USD $=9000$ Rupiah). Test of significance of variance carried out by form $\mathrm{Z}$ = (estimate)/ (standard error of estimate), where $\mathrm{Z}$ is referred to standard normal distribution as known as Wald test (Wald, 1943). The standard errors are asymptotic, which means valid for 
large samples. Looking at the estimation results, all are significant (Table 4). The estimation results shows that maintenance cost not only vary among vehicle group but also among vehicle under similar group. The results also show high percentage of unobserved variances which cannot explain by Null Model. Thus, it is necessary to apply Full model with explanatory variables (fixed variables). Full model was applied to examine how much of above unobserved variances of components can be explained by observed information. The estimation results of Full model are presented in Table 4. Explanatory variables were selected based on the bivariate probit model. To examine significance test between Null and Full model, chi-squared test was applied by using log likelihood estimation results and compare it with Normal distribution test. The results of Full model show estimation is significant and better statistical performance and also interpretable. Looking at random effects, vehicle-level variance $\sigma_{\mathrm{e}}{ }^{2}$ and group-level variance $\sigma_{\mu 0}{ }^{2}$ are goes down. We also found improvement on statistical measures such as AIC, BIC and log likelihood.

In our full model, vehicle level $\sigma_{\mathrm{e}}{ }^{2}$ almost zero which means almost all variance can be explained by selected explanatory variables. Looking at decompose components of vehicle characteristics, it was found maintenance cost of small cars (Engine size $<1000 \mathrm{cc}$ ) are cheaper and differ significantly compare to big size car (Engine size $>2000 \mathrm{cc}$ ). The other components are insignificant to maintenance cost. The pollutants level reduction also gives positive impact on cost but it is not statistically significant. Looking at detail explanatory variables of maintenance actions, eight among twelve actions give significant impact on cost. Six actions positively increase maintenance cost but only two actions may reduce cost significantly. The highest variance component of cost is changing engine oil (64\%) follows by replacement of air filter (58\%). On the other hand, by repairing air filter and tune-up carburetor or injection, vehicle owner can reduce cost around $58 \%$ and $36 \%$ respectively.

\subsection{Simultaneous impact of variation of actions on emission test and maintenance cost}

The estimation results (Table 4) shows actual cost increase whenever vehicle owner replace equipments and perform tune-up fire system, change engine oil and do other 'action' during maintenance process. It was also found although actual cost increase due to replacement with new engine parts, probability to pass emission test doesn't differ significantly compare to repairmen engine parts which is common practices in the developing countries (Harrington, 1996). In order to maximize results on the $2^{\text {nd }}$ emission test and simultaneously reduce maintenance cost, it is necessary to analyze effectiveness of actions on emission reduction and its influence on maintenance cost. In actual situation, owner may choose combination of several actions simultaneously, due to data limitation, in this paper we analyze individual action and its impact on emission and cost. Off course it wasn't reflect real situation, but at least we could provide information to vehicle owner to maximize output and minimize cost during maintenance process.

Looking at the estimation results in Table 5, if action increases probability to pass $\mathrm{CO}, \mathrm{HC}$ and jointly $\mathrm{CO}$ and $\mathrm{HC}$ emission test in the $2^{\text {nd }}$ stage, put positive sign in Table 5 and vice versa. Then, if the action increases cost and statistically significant, also put positive sign and vice versa. Furthermore, how much increasing or decreasing probability to pass and cost variation will quantified in percentage and compare to average values. The first priority should be given to the combination of $(+) /(-)$ which means increase probability to pass emission test in the second period but owner will receive cost reduction compare to average cost. On the other hand, vehicle owner need to avoid combination of $(-) /(+)$ which mean reduce probability but rise maintenance cost. Based on our estimation result in Table 3 and Table 4, first priority in the maintenance process is 'Repair Air Filter'. It will increase probability to pass $\mathrm{CO}$ emission around $39.7 \%$, but vehicle owner can reduce maintenance cost around $58 \%$ compare to the average. Second priority should be given to repairmen of platina since it will increase not only probability to pass $2^{\text {nd }}$ emission test of $\mathrm{HC}$ around $84.7 \%$ and also simultaneously increase join probability to pass $\mathrm{CO}$ and $\mathrm{HC}$ around $19.9 \%$. It will slightly increase maintenance cost around $27 \%$. Furthermore, replacement of platina increase probability on $\mathrm{HC}$ around $48.4 \%$ and join probability of $\mathrm{HC}$ and $\mathrm{CO}$ around $10 \%$ but vehicle owner need to pay more expensive on maintenance cost around $44.02 \%$ compare to average maintenance cost. It was also found that tune up engine fire system increase probability to pass $\mathrm{CO}$ emission test around $30.5 \%$ and simultaneously increase maintenance cost around $30.4 \%$. Furthermore, we didn't recommend the owner to Change oil and replace air filter during I/M program, because it will increase cost $63.6 \%$ and $58 \%$ respectively but there is no significant impact on probability to pass $\mathrm{CO}$ and $\mathrm{HC}$ emission test. However, it will affect on engine performance, so vehicle owner recommended to change engine oil and air filter on regularly schedule rather than incidentally during maintenance process under I/M program. It is also recommended to avoid 'other' action, because it reduces probability to pass $\mathrm{HC}$ emission test around $27.7 \%$ and also reduce probability to pass both $\mathrm{CO}$ and $\mathrm{HC}$ around $7.3 \%$, but vehicle owner need to pay additional cost around $32 \%$ than average maintenance cost. 


\section{Conclusions and Future Research Issues}

In this study, first, we evaluate effectiveness of some actions during maintenance process on vehicle emissions. In the second step, evaluate influential factors of vehicle characteristics, emission load actions taken during process on total repair cost. The bivariate probit regression model applied to examine probability to pass second stage emission test of vehicles after maintenance in Jakarta city. Furthermore, this paper performs multilevel analysis to evaluate factors affects on total maintenance cost.

This study successfully confirmed characteristic of vehicle, emission load and maintenance's action significantly associated with fruitfulness of emission test of Carbon Monoxide and Hydrocarbon. Some efforts may increase probability to pass $\mathrm{CO}$ emission test but simultaneously reduce probability to pass $\mathrm{HC}$ emission test results. The effort to improve $\mathrm{CO}$ concentration is influenced by basic level of its pollutants. The effort to improve $\mathrm{CO}$ emission also influence by prior maintenance level of vehicles. Basically, repair or replace 'platina' will increase join probability to pass $\mathrm{CO}$ and $\mathrm{HC}$ emission test. In contrast, the 'other' action decrease join probability to pass $\mathrm{CO}$ and $\mathrm{HC}$ emission test.

This study also confirmed the influential factors of vehicle characteristics and action taken during maintenance process on actual repair cost. It was found that engine size positively affects on repair cost, increasing engine size of car will automatically increase repair cost. It is acceptable and follows logical framework. Pollutant load which mean pollutant level that should be reduces refers to the Jakarta's standard show positive but insignificant on maintenance cost. Several actions may increase probability to pass emission test but reduce cost. Other action may simultaneously increase probability to pass emission test and also increase cost. The owner need to avoid the action that do not give impact on emission test but increase cost nor action that reduce probability to pass emission test but increase maintenance cost. In order to maximize action but minimize cost, auto-mechanic staff and vehicle owner need to select proper actions. In this study, we analyze the individual action, but in actual case, only few auto-mechanic staff offers single action. Usually, they offer combination of action, and it should be analyze in the next near future research article.

\section{References}

A. A. Abdel-Rahman. (1998). On the Emission from Internal-Combustion Engines: A Review. International Journal of Energy Research, 22, 483-513. http://dx.doi.org/10.1002/(SICI)1099-114X(199805)22:6<483::AIDER377>3.0.CO;2-Z

Adianto P. Simamora. (2006). "Garages ask for speedier emission testing approval." The Jakarta Post-The Journal of Indonesia Today, City News. [Online] Available: http://www.thejakartapost.com (May 1, 2006)

Badan Pengelolaan Lingkungan Hidup Daerah, Propinsi DKI Jakarta. (2005) Kumpulan Peraturan Tentang Pengendalian Pencemaran Udara di Propinsi DKI Jakarta, BPLHD.

Greene, W. (2002). Econometric Analysis. New Jersey: Prentice-Hall.

Harrington, W., Mc Connel, V. D., \& Albertini, A. (1996). Economic incentive policies under uncertainty' the case of vehicle emission fees, Resource for the future. Discussion paper, 99-32, Washington DC. [Online] Available: http://www.rff.org/Publications/Pages/PublicationDetails.aspx?PublicationID=17148

Joop J. Hox. (2010). Multilevel Analysis, Techniques and Applications. New York: Routledge. pp 155.

Nugroho, S. B., A. Fujiwara, J. Zhang. (2010). Vehicle Maintenance Impacts on Idle Emission Test in Jakarta City. roceeding of the Twelfh International Summer Symposium. International Activities Committee, Japan Society of Civil Engineers, 327-330.

Nugroho, S. B., A. Fujiwara, \& J. Zhang. (2010). Comparison Analysis of repair versus Replacement in the Maintenance of Non-compliance vehicle in Jakarta city. The proceeding of the $9^{\text {th }}$ East Asia Society of Transport Studies, Volume 9, 2011.

Rubin, E. S. (2001) Introduction to Engineering and the Environment. McGraw-Hill International Edition, Singapore. 
Table 1. Variables Definition in the Study

\begin{tabular}{|c|c|c|c|}
\hline No & Variables & \multicolumn{2}{|l|}{ Definitions } \\
\hline A & Emission Indicator & \multicolumn{2}{|l|}{$\begin{array}{ll}\text { a. } & \text { Pass_CO }=\mathrm{CO}(\%)<\text { standard }(1 \text { otherwise }=0) \\
\text { b. } & \text { Pass_HC }=\mathrm{HC}(\mathrm{ppm})<\operatorname{standard}(1 \text { otherwise }=0) \\
\text { c. } & \text { P_NRCO }=\mathrm{CO} \text { need to be reduces }(\%) \\
\text { d. } & \text { P_NRHC }=\mathrm{HC} \text { need to be reduces }(\%)\end{array}$} \\
\hline $\mathrm{B}$ & Vehicle Characteristic & \multicolumn{2}{|c|}{$\begin{array}{l}\text { a. AGECD : Passenger Car age, substitute from } 2001 \text { to avoid zero value } \\
\text { b. RKTYRCD: Running Kilometer per year. } \\
\text { c. ENGSZCD: Engine Size displacement (cc) } \\
\text { d. AFRCD: Air to Fuel Ratio (Dummy Variable Maintenance Quality) }\end{array}$} \\
\hline $\mathrm{C}$ & Maintenance actions & \multicolumn{2}{|c|}{$\begin{array}{ll}\text { a. } & \text { RPR_A_FLT; Repair Air Filter }(1=\text { take this action; otherwise }=0) \\
\text { b. } & \text { RPR_FL_FL; Repair Fuel`s filter }(1=\text { take this action; otherwise }=0) \\
\text { c. } & \text { RPR_SPARK; Repair Spark Ignition }(1=\text { take this action; otherwise }=0) \\
\text { d. } & \text { RPR_PLT; Repair 'Platina` }(1=\text { take this action; otherwise }=0) \\
\text { e. } & \text { RPL_A_FLT; Replacing Air Filter }(1=\text { take this action; otherwise }=0) \\
\text { f. } & \text { RPL_FL_FL; Replacing Fuel's filter }(1=\text { take this action; otherwise }=0) \\
\text { g. } & \text { RPL_SPARK; Replacing Spark Ignition }(1=\text { take this action; otherwise }=0) \\
\text { h. } & \text { RPL_PLT; Replacing 'Platina` }(1=\text { take this action; otherwise }=0) \\
\text { i. } & \text { T_C_INJ; Tune-up the carburetor or injections }(1=\text { take action; otherwise }=0) \\
\text { j. } & \text { T_FIRE_S; Tune-up the engine`s burning system }(1=\text { take action; } \\
& \text { otherwise }=0) \\
\text { k. } & \text { OIL_CHG; }(1=\text { take this action; otherwise }=0) \\
\text { 1. } & \text { OTHER; }(1=\text { take this action; otherwise }=0)\end{array}$} \\
\hline $\mathrm{D}$ & Cost & a. $\quad$ costths $=$ Total repair cost paid by the owner in thou & rupiah \\
\hline E & Jakarta`s Standard & $\begin{array}{l}\text { a. Carburetor : } \\
\text { (i) Model Year < } 1986 \text { (CO: } 4.0 \& \text { HC: } 1000) \\
\text { (ii) 1986<Model Year<1996 (CO: 3.5 \& HC: } 800) \\
\text { (iii) 1996>Model Year (CO: } 3.0 \& \text { HC 700) } \\
\text { b. Injection : } \\
\text { (iv) Model Year < } 1996(\mathrm{CO}=3.0 \& \mathrm{HC}=600) \\
\text { (ii) 1996>Model year }(\mathrm{CO}=2.5 \& \mathrm{HC}=500)\end{array}$ & $\begin{array}{l}\text { (group 1) } \\
\text { (group 2) } \\
\text { (group 3) } \\
\text { (group 4) } \\
\text { (group 5) }\end{array}$ \\
\hline
\end{tabular}


Table 2. Vehicle characteristics which fail in the $1^{\text {st }}$ emission test

\begin{tabular}{|c|c|c|c|}
\hline Variable & Definitions & Fail the $1^{\text {st }}$ Test & Pass the $2^{\text {nd }}$ Test \\
\hline & Samples (N) & 675 & 548 \\
\hline $\mathrm{CO}$ & Carbon monoxide (\% vol) & $5.22(2.005)$ & $1.637(0.694)$ \\
\hline $\mathrm{HC}$ & Hydrocarbon (ppm) & $562.95(501.019)$ & $357.64(129.840)$ \\
\hline \multirow[t]{4}{*}{ ENGSZCD } & (1) Engine Size $\leq 1000 \mathrm{cc}$ & $3.9 \%$ & $4.0 \%$ \\
\hline & (2) $1000<$ Engine Size $\leq 1500 \mathrm{cc}$ & $24.2 \%$ & $25.5 \%$ \\
\hline & (3) $1500<$ Engine Size $\leq 2000 \mathrm{cc}$ & $69.9 \%$ & $68.4 \%$ \\
\hline & (4) $2000 \mathrm{cc}<$ Engine Size & $2.1 \%$ & $2.0 \%$ \\
\hline \multirow[t]{6}{*}{ AGECD } & (1) 1 - 3 years & $26.9 \%$ & $26.6 \%$ \\
\hline & (2) 4-6 years & $48.2 \%$ & $48.2 \%$ \\
\hline & (3) 7-9 years & $13.1 \%$ & $13.0 \%$ \\
\hline & (4) $10-12$ years & $8.8 \%$ & $9.1 \%$ \\
\hline & (5) $13-15$ years & $2.2 \%$ & $2.2 \%$ \\
\hline & $(6)>15$ years & $0.9 \%$ & $0.9 \%$ \\
\hline \multirow[t]{6}{*}{ RKTYRCD } & (1) $\mathrm{RKTYR} \leq 10000 \mathrm{~km} / \mathrm{yr}$ & $43.3 \%$ & $42.5 \%$ \\
\hline & (2) $10000<$ RKTYR $\leq 20000$ & $36.8 \%$ & $37.6 \%$ \\
\hline & (3) $20000<$ RKTYR $\leq 30000$ & $14.7 \%$ & $14.6 \%$ \\
\hline & (4) $30000<$ RKTYR $\leq 40000$ & $2.8 \%$ & $3.1 \%$ \\
\hline & (5) $40000<$ RKTYR $\leq 50000$ & $0.9 \%$ & $0.7 \%$ \\
\hline & (6) $50000<$ RKTYR & $1.5 \%$ & $1.5 \%$ \\
\hline I/M Quality & Air to fuel ratio(Lambda) & & \\
\hline Very Good & $0.95 \leq \lambda<1.05$ & $12.0 \%$ & $67.2 \%$ \\
\hline Good & $0.9 \leq \lambda<0.95 \& 1.05 \leq \lambda<1.1$ & $19.3 \%$ & $25.4 \%$ \\
\hline Moderate & $0.85 \leq \lambda<0.9 \& 1.1 \leq \lambda<1.15$ & $29.5 \%$ & $2.7 \%$ \\
\hline $\mathrm{Bad}$ & $0.8 \leq \lambda<0.85 \& 1.15 \leq \lambda<1.2$ & $19.0 \%$ & $1.3 \%$ \\
\hline Very bad & $\lambda<0.8 \& 1.2 \leq \lambda$ & $20.2 \%$ & $3.5 \%$ \\
\hline
\end{tabular}

Notes: In each cell, indicates the mean and inside the brackets indicates the standard deviations. 
Table 3. Estimation result of Bivariate Probit Model of maintenance effect on probability to pass emission test

\begin{tabular}{|c|c|c|c|c|}
\hline \multirow{3}{*}{ Variable } & \multicolumn{2}{|c|}{ Fixed Effect } & \multirow{2}{*}{$\begin{array}{c}\text { Marginal Effect } \\
E\left[\mathrm{y}_{1} \mid \mathrm{y}_{2}=1\right]=0.169\end{array}$} & \multirow{2}{*}{$\begin{array}{c}\text { Effect Dummy } \\
\text { Variable } \\
\mathrm{E}\left[\mathrm{y}_{1} \mid \mathrm{y}_{2}=1, \mathrm{~d}=1\right] \\
-\mathrm{E}\left[\mathrm{y}_{1} \mid \mathrm{y}_{2}=1, \mathrm{~d}=0\right]\end{array}$} \\
\hline & Pass CO ( $2^{\text {nd }}$ Test $)$ & Pass HC ( $2^{\text {nd }}$ Test $)$ & & \\
\hline & Beta (t-score) & Beta (t-score) & Beta (t-score) & Beta (t-score) \\
\hline Constant & $0.899(2.399)$ & $-1.064(-2.668)$ & - & - \\
\hline \multicolumn{5}{|l|}{ Vehicle Characteristics } \\
\hline Running kilometer per year (RKTYRCD) & $0.017(0.278)$ & $0.003(0.053)$ & $0.001(0.083)$ & - \\
\hline Prior Maintenance Level (AFRCD-BF) & $0.195(3.990)$ & $0.005(0.124)$ & $0.007(0.599)$ & - \\
\hline Engine Size (ENGSZCD) & $-0.183(-1.633)$ & $0.058(0.504)$ & $0.009(0.324)$ & \\
\hline \multicolumn{5}{|l|}{ Pollutant Level } \\
\hline CO plus HC Reduction (COPLUSHC) & $0.0008(1.887)$ & $0.0002(1.305)$ & $0.0009(1.509)$ & - \\
\hline \multicolumn{5}{|l|}{ Maintenance Actions } \\
\hline RPR_A_FLT (Repair air filter) & $0.397(1.788)$ & $0.185(0.673)$ & $0.058(0.857)$ & $0.056(0.920)$ \\
\hline RPR_FL_FL (Repair fuel filter) & $-0.377(-1.696)$ & $-0.002(0.009)$ & $-0.011(-0.181)$ & $-0.011(-0.173)$ \\
\hline RPR_SPARK (Repair Spark Ignition) & $0.196(0.994)$ & $-0.351(-1.706)$ & $-0.084(-1.611)$ & $-0.083(-1.636)$ \\
\hline RPR_PLT (Repair Platina) & $-0.628(-3.622)$ & $0.847(4.685)$ & $0.199(4.374)$ & $0.232(3.892)$ \\
\hline RPL_A_FLT (Replace air filter) & $0.186(0.722)$ & $0.315(1.122)$ & $0.086(1.232)$ & $0.095(1.125)$ \\
\hline RPL_FL_FL (Replace fuel filter) & $-0.369(-1.494)$ & $-0.184(-0.691)$ & $-0.058(-0.869)$ & $-0.055(-0.938)$ \\
\hline RPL_SPARK (Replace Spark Ignition) & $0.176(0.870)$ & $-0.164(-0.818)$ & $-0.036(-0.722)$ & $-0.036(-0.743)$ \\
\hline RPL_PLT (Replace Platina) & $-0.497(-2.398)$ & $0.484(2.589)$ & $0.109(2.323)$ & $0.121(2.083)$ \\
\hline T_C_INJ (Tune-up carburetor/injection) & $-0.256(-1.526)$ & $-0.040(-0.254)$ & $-0.017(-0.430)$ & $-0.017(-0.424)$ \\
\hline T_FIRE_S (Tune-up engine fire system) & $0.305(1.711)$ & $0.036(0.203)$ & $0.017(0.391)$ & $0.018(0.405)$ \\
\hline OIL_CHG (Change engine oil) & $-0.090(-0.695)$ & $-0.162(-1.205)$ & $-0.044(-1.296)$ & $-0.044(-1.272)$ \\
\hline OTHER (Other action) & $-0.057(-0.420)$ & $-0.277(-1.975)$ & $-0.073(-2.052)$ & $-0.069(-2.156)$ \\
\hline Disturbance Correlation (Rho) & \multicolumn{2}{|c|}{$-0.250(-3.020)$} & & \\
\hline Log likelihood function & \multicolumn{2}{|c|}{-637.139} & & \\
\hline Sample size & \multicolumn{4}{|c|}{674} \\
\hline
\end{tabular}


Table 4. Multilevel Analysis of Maintenance Cost (thousand rupiah)

\begin{tabular}{|c|c|c|}
\hline \multirow{3}{*}{ Variable } & \multicolumn{2}{|c|}{ Multilevel Analysis } \\
\hline & Null (Intercept only) Model & Full Model (Fixed components) \\
\hline & Beta (t-score) & Beta (t-score) \\
\hline Intercept & 110.922 & $71.402(2.649)$ \\
\hline \multicolumn{3}{|l|}{ Vehicle Characteristics } \\
\hline Small engine' car $(<1000 \mathrm{cc})$ & & $-44.467(-2.121)$ \\
\hline Medium engine' car $(1001<\mathrm{cc}<2000)$ & & $-12.832(-1.012)$ \\
\hline Running kilometer per year (RKTYR) & & $4.318(1.255)$ \\
\hline Prior Maintenance Level (AFRCD-BF) & & $18.349(0.769)$ \\
\hline \multicolumn{3}{|l|}{ Pollutant Level } \\
\hline CO plus HC Reduction (COPLUSHC) & & $0.050(1.303)$ \\
\hline \multicolumn{3}{|l|}{ Maintenance Actions } \\
\hline RPR_A_FLT (Repair air filter) & & $-41.524(-2.942)$ \\
\hline RPR_FL_FL (Repair fuel filter) & & $7.595(0.568)$ \\
\hline RPR_SPARK (Repair Spark Ignition) & & $-12.988(-1.221)$ \\
\hline RPR_PLT (Repair Platina) & & $19.631(2.039)$ \\
\hline RPL_A_FLT (Replace air filter) & & $41.301(2.681)$ \\
\hline RPL_FL_FL (Replace fuel filter) & & $19.043(1.318)$ \\
\hline RPL_SPARK (Replace Spark Ignition) & & $-4.984(-0.436)$ \\
\hline RPL_PLT (Replace Platina) & & $31.437(2.878)$ \\
\hline T_C_INJ (Tune-up carburetor/injection) & & $-26.184(-3.101)$ \\
\hline T_FIRE_S (Tune-up engine fire system) & & $21.719(2.363)$ \\
\hline OIL_CHG (Change engine oil) & & $45.481(6.059)$ \\
\hline OTHER (Other action) & & $23.002(3.043)$ \\
\hline \multicolumn{3}{|l|}{ Random Part } \\
\hline$\sigma_{\mathrm{e}}^{2}($ Vehicle level $)$ & 97.925 & 0.00000012 \\
\hline$\sigma_{\mu 0}^{2}$ (Group level) & 9661.862 & 7310.6 \\
\hline \multicolumn{3}{|l|}{ Model Performance } \\
\hline AIC & 8076 & 7807 \\
\hline $\mathrm{BIC}$ & 8090 & 7897 \\
\hline$-2 *$ Log likelihood & 8076 & 7868 \\
\hline
\end{tabular}

Note: ( ): t- statistic 
Table 5. Maintenance Impact on Emission Test and Its Cost

\begin{tabular}{|l|c|c|c|}
\hline \multirow{2}{*}{ Maintenance Actions } & \multicolumn{3}{|c|}{ Simultaneous Effects (Probability to Pass $2^{\text {nd }}$ Test / Cost) } \\
\cline { 2 - 4 } & Pass CO & Pass HC & Pass CO and HC \\
\hline Repair Air Filter & $(+) /(-)$ & $/(-)$ & $/(-)$ \\
\hline Repair Fuel Filter & $(-) /$ & $/$ & $/$ \\
\hline Repair Spark Ignition & $/$ & $(-) /$ & $(+) /(+)$ \\
\hline Repair Platina & $(-) /(+)$ & $(+) /(+)$ & $/(+)$ \\
\hline Replace Air Filter & $/(+)$ & $/(+)$ & $/$ \\
\hline Replace Fuel Filter & $/$ & $/$ & $/$ \\
\hline Replace Spark Ignition & $/$ & $/$ & $(+) /(+)$ \\
\hline Replace Platina & $(-) /(+)$ & $(+) /(+)$ & $/(+)$ \\
\hline Tune-up carburetor/injection & $/(-)$ & $/(-)$ & $/(+)$ \\
\hline Tune-up engine fire system & $(+) /(+)$ & $/(+)$ & $(-) /(+)$ \\
\hline Change the Engine-oil & $/(+)$ & $/(+)$ & $(-) /(+)$ \\
\hline Other action & $/(+)$ & & \\
\hline
\end{tabular}

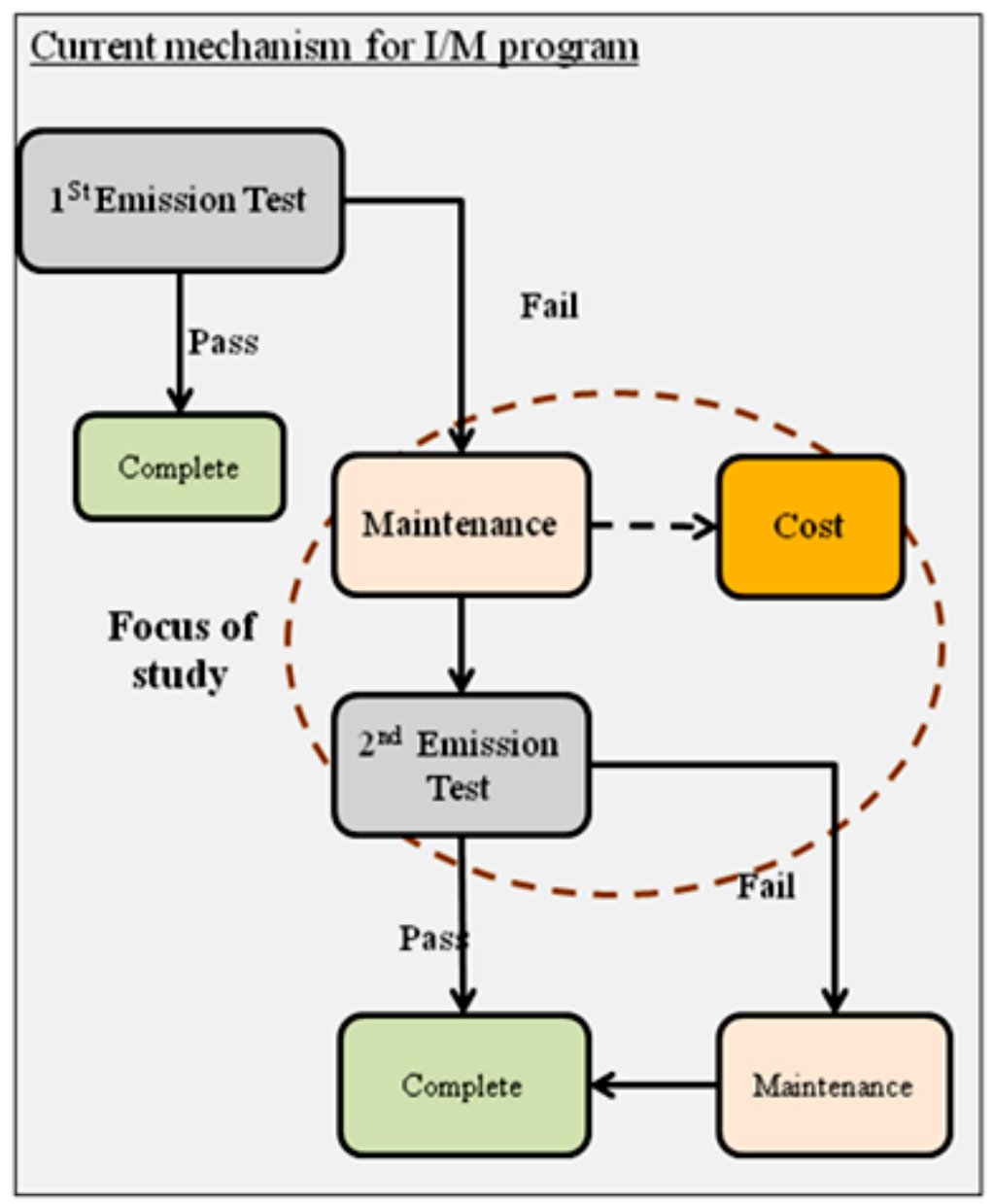

Figure 1. The maintenance flow process in Jakarta city 